\title{
$\alpha 2 \delta$-1 Is Essential for Sympathetic Output and NMDA Receptor Activity Potentiated by Angiotensin II in the Hypothalamus
}

\author{
Huijie Ma (马会杰), ${ }^{1,2}$ Shao-Rui Chen (陈少瑞), ${ }^{1}$ Hong Chen (陈红), ${ }^{1}$ Lingyong Li (李令勇), ${ }^{1}$ De-Pei Li (李德培), ${ }^{1}$ \\ - OJing-Jing Zhou (周京京), ${ }^{1}$ and Hui-Lin Pan (潘惠麟) ${ }^{1}$ \\ ${ }^{1}$ Center for Neuroscience and Pain Research, Department of Anesthesiology and Perioperative Medicine, The University of Texas MD Anderson Cancer \\ Center, Houston, Texas 77030 and 2Department of Physiology, Hebei Medical University, Shijiazhuang, Hebei 050017, China
}

Both the sympathetic nervous system and the renin-angiotensin system are critically involved in hypertension development. Although angiotensin II (Ang II) stimulates hypothalamic paraventricular nucleus (PVN) neurons to increase sympathetic vasomotor tone, the molecular mechanism mediating this action remains unclear. The glutamate NMDAR in the PVN controls sympathetic outflow in hypertension. In this study, we determined the interaction between $\alpha 2 \delta$-1 (encoded by Cacna2d1), commonly known as a Ca ${ }^{2+}$ channel $^{2}$ subunit, and NMDARs in the hypothalamus and its role in Ang II-induced synaptic NMDAR activity in PVN presympathetic neurons. Coimmunoprecipitation assays showed that $\alpha 2 \delta-1$ interacted with the NMDAR in the hypothalamus of male rats and humans (both sexes). Ang II increased the prevalence of synaptic $\alpha 2 \delta$-1-NMDAR complexes in the hypothalamus. Also, Ang II increased presynaptic and postsynaptic NMDAR activity via AT1 receptors, and such effects were abolished either by treatment with pregabalin, an inhibitory $\alpha 2 \delta$-1 ligand, or by interrupting the $\alpha 2 \delta$-1-NMDAR interaction with an $\alpha 2 \delta$-1 C terminus-interfering peptide. In Cacna2d 1 knock-out mice (both sexes), Ang II failed to affect the presynaptic and postsynaptic NMDAR activity of PVN neurons. In addition, the $\alpha 2 \delta-1 \mathrm{C}$ terminus-interfering peptide blocked the sympathoexcitatory response to microinjection of Ang II into the PVN. Our findings indicate that Ang II augments sympathetic vasomotor tone and excitatory glutamatergic input to PVN presympathetic neurons by stimulating $\alpha 2 \delta$-1-bound NMDARs at synapses. This information extends our understanding of the molecular basis for the interaction between the sympathetic nervous and renin-angiotensin systems and suggests new strategies for treating neurogenic hypertension.

Key words: autonomic nervous system; gabapentin; gabapentinoids; presynaptic NMDA receptor synapse; synaptic plasticity

\section{Significance Statement}

Although both the sympathetic nervous system and renin-angiotensin system are closely involved in hypertension development, the molecular mechanisms mediating this involvement remain unclear. We showed that $\alpha 2 \delta$-1, previously known as a calcium channel subunit, interacts with NMDARs in the hypothalamus of rodents and humans. Angiotensin II (Ang II) increases the synaptic expression level of $\alpha 2 \delta$-1-NMDAR complexes. Furthermore, inhibiting $\alpha 2 \delta$-1, interrupting the $\alpha 2 \delta$-1-NMDAR interaction, or deleting $\alpha 2 \delta$-1 abolishes the potentiating effects of Ang II on presynaptic and postsynaptic NMDAR activity in the hypothalamus. In addition, the sympathoexcitatory response to Ang II depends on $\alpha 2 \delta$-1-bound NMDARs. Thus, $\alpha 2 \delta$-1-NMDAR complexes in the hypothalamus serve as an important molecular substrate for the interaction between the sympathetic nervous system and the renin-angiotensin system. This evidence suggests that $\alpha 2 \delta$-1 may be a useful target for the treatment neurogenic hypertension.

\section{Introduction}

Both the sympathetic nervous system and renin-angiotensin system have a central role in hypertension development. Increased

Received Feb. 19, 2018; revised June 12, 2018; accepted June 13, 2018.

Author contributions: H.-L.P. designed research; H.M., S.-R.C., H.C., L.L., D.-P.L., and J.-J.Z. performed research; H.M., S.-R.C., and H.-L.P. analyzed data; H.-L.P. wrote the paper.

This work was supported by the National Institutes of Health (Grants HL131161, HL139523, and HL142133) and the N.G. and Helen T. Hawkins Endowment (to H.-L.P.). Human brain tissues were obtained from the Brain and Tissue Bank at the University of Maryland, a repository funded by the National Institutes of Health NeuroBioBank.

The authors declare no competing financial interests. sympathetic nerve activity not only results in direct vasoconstriction but also increases renin secretion from the kidney (Richardson et al., 1974). Increased renin release results in the generation of angiotensin I, which is then converted to angiotensin II (Ang II), the major effector peptide of the renin-angiotensin system,

Correspondence should be addressed to Dr. Hui-Lin Pan, Department of Anesthesiology and Perioperative Medicine, Unit 110, The University of Texas MD Anderson Cancer Center, 1515 Holcombe Blvd, Houston, TX 77030. E-mail: huilinpan@mdanderson.org.

DOI:10.1523/JNEUROSCI.0447-18.2018

Copyright $\odot 2018$ the authors $\quad 0270-6474 / 18 / 386388-11 \$ 15.00 / 0$ 
leading to Ang II-induced vasoconstriction and antinatriuresis (Edwards et al., 1986; DiBona, 2000). In hypertensive conditions, circulating Ang II can access brain regions to stimulate presympathetic neurons in the brain (Zhang et al., 2010; Biancardi et al., 2014), resulting in heightened sympathetic vasomotor tone. However, the cellular and molecular mechanisms involved in the interaction between the sympathetic nervous system and the renin-angiotensin system remain uncertain.

Forebrain structures, especially the hypothalamic paraventricular nucleus (PVN), are critically involved in the control of the sympathetic nervous system and play an important role in the pathogenesis of hypertension (Eilam et al., 1991; Allen, 2002; Li and Pan, 2007). The PVN represents the rostral extension of a serial connection of sympathetic-related neurons extending caudally to the spinal cord (Strack et al., 1989; Coote et al., 1998). The rostral ventrolateral medulla (RVLM) and spinal intermediolateral cell column (IML) neurons receive abundant, highly organized projections from the PVN, and the PVN neurons that project to the RVLM and spinal IML are considered presympathetic neurons. Ang II can stimulate PVN presympathetic neurons to augment sympathetic outflow (Li et al., 2003, 2006; Wang et al., 2013; Khanmoradi and Nasimi, 2016). Increased glutamate NMDAR activity also leads to augmented glutamatergic input to PVN presympathetic neurons and sympathetic outflow in hypertension (Li and Pan, 2007; Li et al., 2008; Qiao et al., 2017). Deletion of the NMDAR subunit GluN1 in the PVN attenuates Ang II-induced increases in blood pressure in mice (Glass et al., 2015). Nevertheless, it is still unclear whether and how Ang II affects presynaptic or postsynaptic NMDARs in the PVN.

Generally known as a voltage-activated $\mathrm{Ca}^{2+}$ channel (VACC) subunit, $\alpha 2 \delta-1$ (encoded by Cacna2d1), is the binding site of gabapentinoids, including gabapentin and pregabalin (Gee et al., 1996; Marais et al., 2001; Fuller-Bicer et al., 2009), which are widely used to treat neuropathic pain and epilepsy. For many years, $\alpha 2 \delta$-1 has been assumed to be involved exclusively in the regulation of VACCs. However, gabapentinoids have little effect on VACC activity (Rock et al., 1993; Schumacher et al., 1998; Chen et al., 2018) or VACC-mediated neurotransmitter release at presynaptic terminals (Brown and Randall, 2005; Hoppa et al., 2012). We recently discovered that $\alpha 2 \delta$ - 1 is an interacting protein of NMDARs in the spinal cord (Chen et al., 2018). Although $\alpha 2 \delta$ - 1 is highly expressed in the PVN (Cole et al., 2005; Taylor and Garrido, 2008), researchers still do not know whether $\alpha 2 \delta$-1 plays a role in Ang II signaling in the PVN. In this study, we wanted to find out whether $\alpha 2 \delta$-1 can interact with NMDARs and mediate the action of Ang II in the PVN. We demonstrated that Ang II increases presynaptic and postsynaptic NMDAR activity by potentiating the synaptic trafficking of $\alpha 2 \delta$-1-bound NMDARs. Our study shows for the first time that $\alpha 2 \delta$-1-bound NMDARs serve as a key molecular mechanism for Ang II's action in the hypothalamus and for the interaction between the sympathetic nervous system and the renin-angiotensin system.

\section{Materials and Methods}

Animals. We used 10-12-week-old male Sprague Dawley rats (Harlan Sprague Dawley) and both male and female mice (C57BL/6 genetic background) in our experiments. Two breeding pairs of Cacna2d $1^{+/-}$mice were purchased from Medical Research Council, and Cacna2d1 $1^{-1-}$ (knock-out) mice and Cacna2d1 ${ }^{+/+}$(wild-type) littermates were obtained by breeding the heterozygous mice. Because we found no sex differences in the effect of Ang II on synaptic NMDAR activity, electrophysiological data from male and female mice were pooled. All surgical preparation and experimental protocols were approved by the Animal Care and Use Committee of The University of Texas MD Anderson
Cancer Center and conformed to the National Institutes of Health guidelines for the ethical use of animals. All efforts were made to minimize both the suffering and the number of animals used.

Retrograde labeling of spinally projecting PVN neurons. Rats or mice were anesthetized with $2-3 \%$ isoflurane, and their spinal cords at the T1-T4 level were exposed through dorsal laminectomy. A fluorescent microsphere suspension (FluoSpheres, $0.04 \mu \mathrm{m}$; Invitrogen) was pressure ejected (Nanoject II Microinjectors, Drummond Scientific Company) bilaterally into the IML region of the spinal cord in six separate 50 $\mathrm{nl}$ injections using a glass micropipette (tip diameter, 20-30 $\mu \mathrm{m}$ ). The tracer injection was monitored through a surgical microscope (Li et al., 2002, 2003). The wound was closed with sutures after injection. Animals were returned to their cages for $4-7 \mathrm{~d}$, which was sufficient time to permit the tracer to be retrogradely transported to the PVN. The animals were inspected daily for motor activity, signs of infection, and food and water intake.

Brain slice preparation. Four to $7 \mathrm{~d}$ after fluorescent tracer injection, the animals were anesthetized with isoflurane and immediately decapitated. The brain was quickly removed and placed in ice-cold artificial CSF (aCSF) saturated with $95 \% \mathrm{O}_{2}$ and $5 \% \mathrm{CO}_{2}$. A tissue block containing the hypothalamus was cut from the brain and glued onto the stage of a vibratome (Leica VT1000 S, Leica Biosystems) as described previously (Li et al., 2003; Ye et al., 2011). Coronal slices (thickness, $300 \mu \mathrm{m}$ ) containing the PVN were cut from the tissue block in the ice-cold aCSF. The slices were preincubated in aCSF, which was continuously gassed with $95 \% \mathrm{O}_{2}$ and $5 \% \mathrm{CO}_{2}$ at $34^{\circ} \mathrm{C}$ for $\geq 1 \mathrm{~h}$ before being used for recording. The perfusion solution contained the following (in mmol/L): $126 \mathrm{NaCl}$, $3 \mathrm{KCl}, 1.5 \mathrm{MgCl}_{2}, 2.4 \mathrm{CaCl}_{2}, 1.2 \mathrm{NaH}_{2} \mathrm{PO}_{4}, 11$ glucose, and $26 \mathrm{NaHCO}_{3}$ (300-310 $\mathrm{mOsmol} / \mathrm{L})$. The brain slices were placed in a glass-bottom chamber and continuously perfused with aCSF at $3.0 \mathrm{ml} / \mathrm{min}$ at $34^{\circ} \mathrm{C}$ maintained by an in-line solution heater and temperature controller.

Electrophysiological recordings. The fluorescence-labeled neurons located in the medial one-third of the PVN area between the third ventricle and the fornix were selected for recording (Li et al., 2002, 2003). The labeled PVN neurons were briefly identified with the aid of epifluorescence illumination, and whole-cell recordings from labeled PVN neurons were performed under differential interference contrast optics on an upright microscope (BX50 WI, Olympus Optical). Recordings of postsynaptic currents began 5 min after the whole-cell access was established and the current reached a steady state.

The miniature EPSCs (mEPSCs) were recorded in the presence of $1 \mu \mathrm{mol} / \mathrm{L}$ tetrodotoxin (TTX) and $20 \mu \mathrm{mol} / \mathrm{L}$ bicuculline at a holding potential of $-60 \mathrm{mV}$ (Li et al., 2003; Ye et al., 2011). The recording glass pipette (5-10 M $\Omega$ ) was filled with internal solution containing the following (in $\mathrm{mmol} / \mathrm{L}$ ): 135.0 potassium gluconate, 5.0 tetraethylammonium, 2.0 $\mathrm{MgCl}_{2}, 0.5 \mathrm{CaCl}_{2}$, 5.0 HEPES, 5.0 EGTA, 5.0 Mg-ATP, 0.5 $\mathrm{Na}-\mathrm{GTP}$, and 10 lidocaine $N$-ethyl bromide (adjusted to $\mathrm{pH} 7.2-7.4$ with $1 \mathrm{~m} \mathrm{KOH} ; 290-300 \mathrm{mOsmol} / \mathrm{L})$. Signals were processed with an Axopatch 700B amplifier (Molecular Devices). A liquid junction potential of $15 \mathrm{mV}$ (for the potassium gluconate pipette solution) was corrected during off-line analysis. Signals were filtered at $1-2 \mathrm{kHz}$, digitized at $10 \mathrm{kHz}$ using Digidata 1440A (Molecular Devices), and saved to the computer.

Postsynaptic NMDAR currents were elicited by puff application of 100 $\mu \mathrm{mol} / \mathrm{L}$ NMDA to the recorded neuron using a positive pressure system (4 psi, $50 \mathrm{~ms}$; Toohey). The tip of the puff pipette was placed $150 \mu \mathrm{m}$ from the recorded neuron. The recordings were performed in the $\mathrm{Mg}^{2+}$ free extracellular solution containing $10 \mu \mathrm{mol} / \mathrm{L}$ glycine and $1 \mu \mathrm{mol} / \mathrm{L}$ TTX at a holding potential of $-60 \mathrm{mV}$ (Li et al., 2008; Ye et al., 2011). The pipette internal solution contained the following (in $\mathrm{mmol} / \mathrm{L}$ ): 110.0 $\mathrm{Cs}_{2} \mathrm{SO}_{4}, 2.0 \mathrm{MgCl}_{2}, 0.1 \mathrm{CaCl}_{2}$, 1.1 EGTA, 10.0 HEPES, 2.0 Mg-ATP, 0.3 $\mathrm{Na}_{2} \mathrm{GTP}$, and 10 lidocaine $\mathrm{N}$-ethyl bromide ( $\mathrm{pH}$ was adjusted to 7.25 with $1.0 \mathrm{M} \mathrm{CsOH} ; 280-300 \mathrm{mOsmol} / \mathrm{L}$ ). The puff NMDAR currents were fairly stable during the recordings. The NMDAR current data presented in the manuscript were the average of three consecutive currents elicited by repeated puff NMDA. We discarded the neuron if the current was not stable.

Ang II, losartan, and NMDA were obtained from Sigma-Aldrich. The $\alpha 2 \delta$-1Tat peptide and scrambled control peptide were synthesized by Bio Basic and validated by liquid chromatography and mass spectrometry. Pregabalin was obtained from Tocris Bioscience. TTX and DL-2-amino- 
5-phosphonopentanoic acid (AP5) were purchased from Hello Bio. All drugs were prepared immediately before the experiments and applied to the slice chamber. The brain slices were first pretreated with Ang II, losartan, $\alpha 2 \delta$-1Tat peptide, or control peptide in the slice incubation chamber before recording. For electrophysiological recording, we immediately removed the treatment agents and transferred the brain slice to a separate recording chamber.

Coimmunoprecipitation using hypothalamic tissues. Rat hypothalamic slices containing the PVN were sectioned $1.08-2.12 \mathrm{~mm}$ caudal to the bregma. For each sample used for coimmunoprecipitation assay, we pooled hypothalamic tissues from three rats. The frozen hypothalamic tissues were also obtained from four human donors (two males and two females; age range, 18-36 years; University of Maryland Brain and Tissue Bank). The tissues were dissected and homogenized in ice-cold hypotonic buffer $\left(20 \mathrm{mmol} / \mathrm{L}\right.$ Tris, $\mathrm{pH} 7.4,1 \mathrm{mmol} / \mathrm{L} \mathrm{CaCl}_{2}, 1 \mathrm{mmol} / \mathrm{L} \mathrm{MgCl}_{2}$, and the protease inhibitor mixture) for membrane preparation. The nuclei and unbroken cells were removed by centrifugation at $2,000 \times g$ for $10 \mathrm{~min}$. The supernatant was centrifuged for $30 \mathrm{~min}$ at $21,000 \times g$. The pellets were resuspended and solubilized in immunoprecipitation buffer (50 mmol/L Tris, pH 7.4, $250 \mathrm{mmol} / \mathrm{L} \mathrm{NaCl}, 0.5 \% \mathrm{NP}-40$, and a protease inhibitor mixture), and the soluble fraction was incubated at $4^{\circ} \mathrm{C}$ overnight with Protein G beads (\#16-266, EMD Millipore) prebound to mouse anti-GluN1 antibody (\#75-272, 1:1000, NeuroMab, RRID: $\left.A B \_11000180\right)$. Protein $G$ beads prebound to mouse $\operatorname{IgG}$ were used as controls. Samples were washed three times with immunoprecipitation buffer and then immunoblotted with rabbit anti- $\alpha 2 \delta$ - 1 antibody (1:500; \#ACC-015, Alomone Labs, RRID:AB_2039785).

Protein level analysis in hypothalamic synaptosomes. The hypothalamic tissues containing the PVN (pooled from two rats per sample) were homogenized using 10 volumes of ice-cold HEPES-buffered sucrose ( $0.32 \mathrm{~mol} / \mathrm{L}$ sucrose, $1 \mathrm{mmol} / \mathrm{L}$ EGTA, and $4 \mathrm{mmol} / \mathrm{L}$ HEPES, $\mathrm{pH} 7.4$ ) containing the protease inhibitor mixture (Sigma-Aldrich). The homogenate was centrifuged at $2,000 \times g$ for $10 \mathrm{~min}$ at $4^{\circ} \mathrm{C}$ to remove the nuclei and large debris. The supernatant was centrifuged at $20,000 \times g$ for 30 min to obtain the crude synaptosomal fraction. The synaptosomal pellet was lysed via hypo-osmotic shock in 9 volumes of ice-cold HEPES buffer with the protease inhibitor mixture for $30 \mathrm{~min}$. The lysate was centrifuged at $25,000 \times g$ for $45 \mathrm{~min}$ at $4^{\circ} \mathrm{C}$ to obtain the synaptosomal membrane fraction (Chen et al., 2018), which was then dissolved in SDS sample buffer at a final concentration of $0.25 \mu \mathrm{g} / \mu \mathrm{l}$ for immunoblotting.

Western blotting was used to quantify GluN1 and $\alpha 2 \delta$-1 protein levels in the hypothalamic synaptosome. Fifteen micrograms of total proteins from each sample were loaded and separated by $4-15 \%$ Tris-HCl SDSPAGE (\#456-1086, Bio-Rad). The resolved proteins were transferred to a polyvinylidene difluoride membrane (Millipore). The membrane was treated with $5 \%$ nonfat dry milk in Tris-buffered saline (TBS) at $25^{\circ} \mathrm{C}$ for $1 \mathrm{~h}$ and then incubated in TBS supplemented with $0.1 \%$ Triton X-100, 1\% bovine serum albumin, and rabbit anti-GluN1 (1:100; \#G8913, Sigma-Aldrich, RRID:AB_259978), rabbit anti- $\alpha 2 \delta$-1 (1:500; \#ACC015, Alomone, RRID:AB_2039785), and mouse anti-PSD-95 (1:1000; \#75-348, NeuroMab, RRID:AB_2315909) antibodies overnight at $4^{\circ} \mathrm{C}$. The membrane was washed three times and then incubated with horseradish peroxidase-conjugated anti-rabbit IgG (1:5000; Jackson ImmunoResearch) for $1 \mathrm{~h}$ at room temperature. The protein bands were detected with an enhanced chemiluminescence kit (Thermo Fisher Scientific), and protein band intensity was visualized and quantified using an Odyssey Fc Imager (LI-COR Biosciences). The protein levels of GluN1 and $\alpha 2 \delta$ - 1 were normalized by the PSD-95 protein band on the same gel.

$P V N$ microinjection and recording of renal sympathetic nerve activity. Rats were anesthetized with a mixture of $\alpha$-chloralose ( $60 \mathrm{mg} / \mathrm{kg}$, i.p.) and urethane $(800 \mathrm{mg} / \mathrm{kg}$, i.p.). A retroperitoneal incision was made and a branch of the left renal postganglionic sympathetic nerve was isolated under a surgical microscope. The renal sympathetic nerve was cut distally to ensure that afferent nerve activity was not recorded. The renal sympathetic nerve activity (RSNA), arterial blood pressure (ABP), and heart rate (HR) were recorded using a 1401-PLUS analog-to-digital converter and Spike2 system (Cambridge Electronic Design). A microinjection pipette (tip diameter, $20-30 \mu \mathrm{m}$ ) was advanced into the PVN according to the following stereotactic coordinates: $1.6-2.0 \mathrm{~mm}$ caudal to the bregma,
$0.5 \mathrm{~mm}$ lateral to the midline, and $7.0-7.5 \mathrm{~mm}$ ventral to the dura. The microinjection was done using a calibrated microinjection system (Nanoject II, Drummond Scientific) and monitored using a surgical microscope as described previously (Li and Pan, 2006, 2007; Qiao et al., 2017). Ang II $(200 \mu \mathrm{mol} / \mathrm{L}, 50 \mathrm{nl})$ was microinjected into the PVN to observe the change in RSNA and ABP in the absence or presence of $\alpha 2 \delta$-1Tat peptide $(100 \mu \mathrm{mol} / \mathrm{L}, 50 \mathrm{nl})$ or control peptide $(100 \mu \mathrm{mol} / \mathrm{L}$, $50 \mathrm{nl}$ ). The microinjections were separated by $10-15 \mathrm{~min}$ intervals to allow recovery of the response. To determine the location of the injection site and diffusion of the drugs in the PVN, we included 5\% rhodaminelabeled fluorescent microspheres $(0.04 \mu \mathrm{m}$; Invitrogen $)$ in the injection solution (Li and Pan, 2006, 2007; Qiao et al., 2017).

Study design and data analysis. Data are presented as means \pm SEM. No statistical methods were used to predetermine sample sizes for biochemical studies, but our sample sizes were similar to those generally used in the field. Data collection was randomized, and data distribution was determined using the Kolmogorov-Smirnov normality test. Rats were excluded from analysis if the microinjection site was outside the PVN. In electrophysiological recording experiments, we monitored cell capacitance, input resistance, series resistance, and baseline holding current; we excluded cells if the recording indicated a rundown condition. Only one neuron in each brain slice was recorded, and $\geq 3$ animals were used for each recording protocol. The amplitude and frequency of mEPSCs were analyzed off-line with a peak detection program (MiniAnalysis; Synaptosoft). The cumulative probability of the amplitude and interevent interval was compared using the Kolmogorov-Smirnov test, which estimates the probability that two cumulative distributions are similar. The peak amplitude of puff NMDA-induced currents was determined and analyzed using pClamp and Clampfit 10.2 (Molecular Devices). The mean ABP, RSNA, and HR were analyzed using Spike2 software. The mean ABP was derived from the pulsatile ABP and calculated as the diastolic pressure plus one-third of the pulse pressure. RSNA was rectified and integrated off-line after subtracting the background noise, which was recorded after the proximal end of renal nerve was crushed at the end of each experiment. The integrated RSNA value was calculated and derived from raw RSNA with an integrating time of $1.0 \mathrm{~s}$ using Spike2 software. Control values were obtained by averaging the signal over a $60 \mathrm{~s}$ period immediately before PVN microinjection. Response values after each intervention were averaged over $30 \mathrm{~s}$ when the maximal responses occurred. A two-tailed Student's $t$ test was used to compare two groups, and one-way ANOVA, followed by Dunnett's and Tukey's post hoc tests, was used to compare $>2$ groups. Statistical analyses were performed using Prism 6 software (GraphPad Software). $p<$ 0.05 was considered statistically significant.

\section{Results}

\section{$\alpha 2 \delta$-1 Physically interacts with NMDARs in the hypothalamus of rats and humans}

We recently showed that $\alpha 2 \delta$-1 physically interacts with NMDAR subunits in the spinal cord (Chen et al., 2018). To determine whether $\alpha 2 \delta$ - 1 and NMDARs interact in the hypothalamus, we conducted coimmunoprecipitation analyses using membrane extracts of the rat hypothalamus. Using specific antibodies, $\alpha 2 \delta-1$ was coprecipitated with GluN1, an obligatory subunit of NMDARs (Fig. 1A), whereas the irrelevant IgG did not pull down $\alpha 2 \delta$ - 1 in the hypothalamic tissue.

In addition, the anti-GluN1 antibody, but not IgG, coimmunoprecipitated with $\alpha 2 \delta$-1 in membrane extracts from human hypothalamic tissues ( $n=4$ subjects; Fig. $1 A$ ). These results indicate that $\alpha 2 \delta$-1 physically interacts with NMDARs in the hypothalamus in both rats and humans.

\section{Ang II increases the prevalence of $\alpha 2 \delta$-1-NMDAR complexes in the hypothalamus}

The synaptic NMDARs are highly dynamic and depend on trafficking from their intracellular pool (Tovar and Westbrook, 2002; Chen et al., 2018). We thus determined whether Ang II 

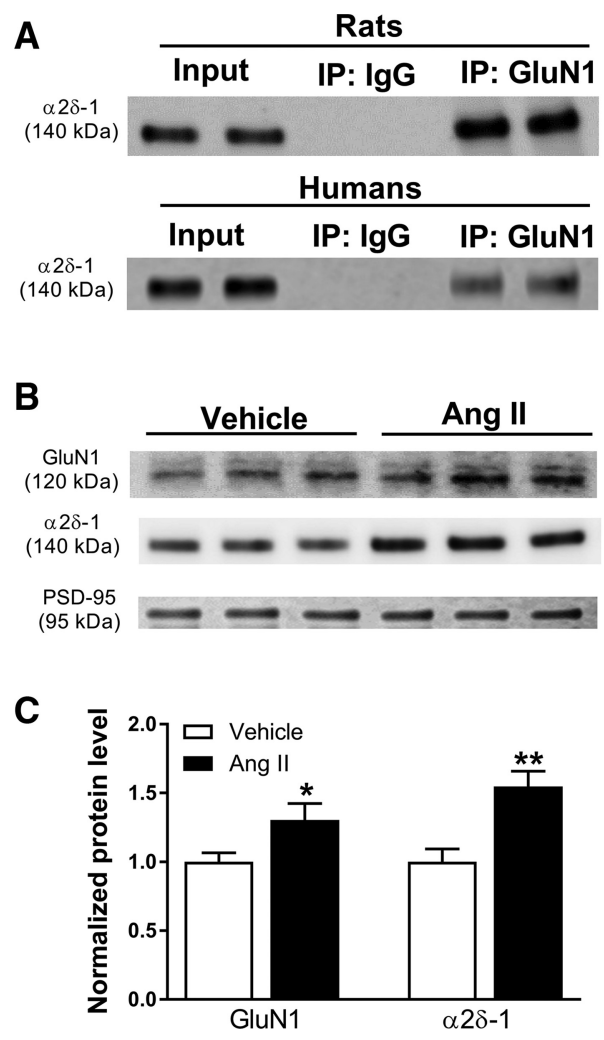

D

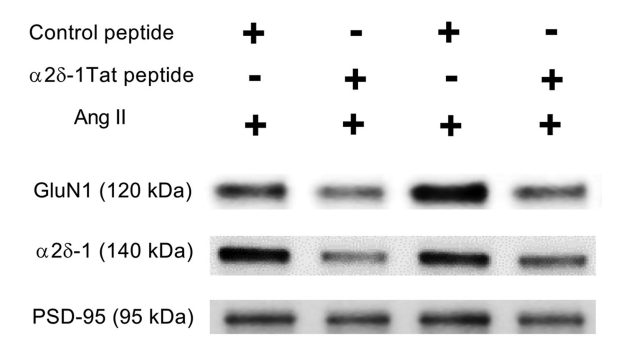

E

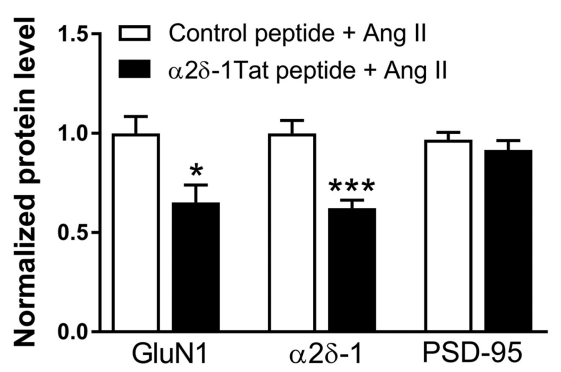

Figure 1. $\alpha 2 \delta$-1 Physically interacts with NMDARs in the hypothalamus, and Ang II increases the synaptic expression level of $\alpha 2 \delta-1-N M D A R$ complexes in the hypothalamus. $A$, Coimmunoprecipitation analysis shows the protein-protein interaction between $\alpha 2 \delta$-1 and GluN1 in the membrane extracts of the hypothalamic tissues from rats (for each sample, tissues were pooled from 3 rats) and humans (2 separate subjects). Proteins were immunoprecipitated first with an anti-GluN1 or lgG. Western immunoblotting was performed by using an anti- $\alpha 2 \delta-1$ antibody. $\boldsymbol{B}, \boldsymbol{C}$, Representative images $(\boldsymbol{B})$ and quantification data $(\boldsymbol{C})$ show the effect of Ang II $(2 \mu \mathrm{mol} / \mathrm{L})$ on the protein level of $\mathrm{GluN} 1$ and $\alpha 2 \delta$ - 1 in the hypothalamic synaptosomes $(n=6$ independent experiments, samples pooled from 2 rats in each group). Data are presented as means $\pm S E M,{ }^{*} p<0.05,{ }^{* *} p<0.01$ compared with the vehicle group. $\boldsymbol{D}, \boldsymbol{E}$, Representative images $(\boldsymbol{D})$ and quantification data ( $\boldsymbol{E}$ ) show the protein levels of GluN1 and $\alpha 2 \delta$-1 in hypothalamic synaptosomes treated with Ang II ( $2 \mu \mathrm{mol} / \mathrm{L})$ plus $\alpha 2 \delta$-1Tat peptide (1 $\mu$ mol/L) or Ang II plus control peptide ( $n=7$ independent experiments; each tissue sample was pooled from 2 rats). The protein levels of GluN1 and $\alpha 2 \delta$ - 1 were normalized to PSD-95 on the same gel (an internal control). The PSD-95 level was calculated by considering the relative density of PSD-95 protein in the control peptide group as 1. Data are presented as means \pm SEM. ${ }^{*} p<0.05,{ }^{* * *} p<0.001$ compared with the control peptide plus Ang II group.

increases synaptic targeting of $\alpha 2 \delta$-1-NMDAR complexes in the PVN. Hypothalamic slices were sectioned $1.08-2.12 \mathrm{~mm}$ caudal to bregma and treated with Ang II $(2 \mu \mathrm{mol} / \mathrm{L})$ or vehicle for 60 $\mathrm{min}$. Synaptosomes were then isolated from the tissue slices. Immunoblotting showed that Ang II significantly increased the protein levels of GluN1 $\left(p=0.043, t_{(10)}=2.237 ; n=12\right.$ rats/group) and $\alpha 2 \delta$ - $1\left(p=0.004, t_{(10)}=3.724, n=12\right.$ rats/group $)$ in hypothalamic synaptosomes (Fig. $1 B, C$ ).

We next determined whether the $\alpha 2 \delta$-1-NMDAR interaction is involved in Ang II-induced increases in the protein levels of GluN1 and $\alpha 2 \delta-1$ at the synaptic sites. Hypothalamic slices were incubated with Ang II for $60 \mathrm{~min}$ in the presence of control peptide or $\alpha 2 \delta$-1Tat peptide. We have shown that the $\mathrm{C}$ terminus of $\alpha 2 \delta-1$ is essential for its interaction with NMDARs and that a 30 aa peptide (VSGLNPSLWSIFGLQFILLWLVSGSRHYLW) mimicking the C-terminal domain of $\alpha 2 \delta$-1 fused with Tat protein (YGRKKRRQRRR) can uncouple the $\alpha 2 \delta$-1-NMDAR interaction (Chen et al., 2018). The effect of Ang II on the protein levels of GluN1 $\left(p=0.014, t_{(12)}=2.862 ; n=14\right.$ rats/group $)$ and $\alpha 2 \delta$-1 $\left(p=0.0003, t_{(12)}=4.956 ; n=14\right.$ rats/group) was significantly attenuated in hypothalamic synaptosomes treated with $\alpha 2 \delta$-1Tat peptide ( $1 \mu \mathrm{mol} / \mathrm{L}$ for $30 \mathrm{~min})$, compared with those treated with a Tat-fused scrambled control peptide (FGLGWQPWSLSFYLVWSGLILSVLHLIRSN; Fig. $1 D, E$ ). These data suggest that Ang II increases the synaptic targeting/trafficking of $\alpha 2 \delta$-1-bound NMDARs in the hypothalamus.
Ang II increases presynaptic and postsynaptic NMDAR activity via AT1 receptors in spinally projecting PVN neurons Systemic administration of Ang II in mice is associated with an increased amplitude of NMDA-elicited currents in PVN neurons (Wang et al., 2013). To determine whether Ang II affects the postsynaptic NMDAR activity in spinally projecting PVN neurons, we recorded the NMDAR current elicited by puff NMDA application directly to labeled PVN neurons. Incubation of brain slices with Ang II ( $2 \mu \mathrm{mol} / \mathrm{L}$ for 30-60 min) markedly increased the amplitude of puff NMDA currents $(n=11$ neurons, $p=$ $0.002, F_{(2,24)}=8.020$; Fig. $\left.2 A-C\right)$. This effect of Ang II on puff NMDAR currents was abolished by coincubation with an angiotensin AT1 receptor antagonist, losartan $(2 \mu \mathrm{mol} / \mathrm{L}, 30 \mathrm{~min} ; n=$ 8 neurons; Fig. $2 B, C)$.

To specifically determine whether Ang II affects the presynaptic NMDAR activity of labeled PVN neurons, we examined the effect of Ang II on mEPSCs, which reflects spontaneous quantal release of glutamate from presynaptic terminals (Ye et al., 2011; Qiao et al., 2017). Incubation of brain slices with Ang II (2 $\mu \mathrm{mol} / \mathrm{L}$ for 30-60 $\mathrm{min}$ ) significantly increased the baseline frequency, but not the amplitude, of the mEPSCs of the retrogradely labeled PVN neurons that project to the spinal cord ( $n=8$ neurons, $p=0.004, F_{(8,60)}=3.295$; Fig. $\left.2 D-H\right)$. Bath application of the NMDAR antagonist AP5 $(50 \mu \mathrm{mol} / \mathrm{L})$ rapidly reversed the Ang II-induced increase in mEPSC frequency, indicating that presynaptic NMDARs mediate the Ang II-induced increase in 
A

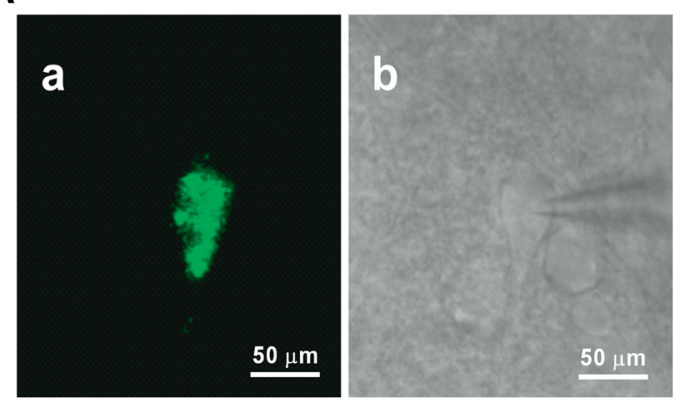

B
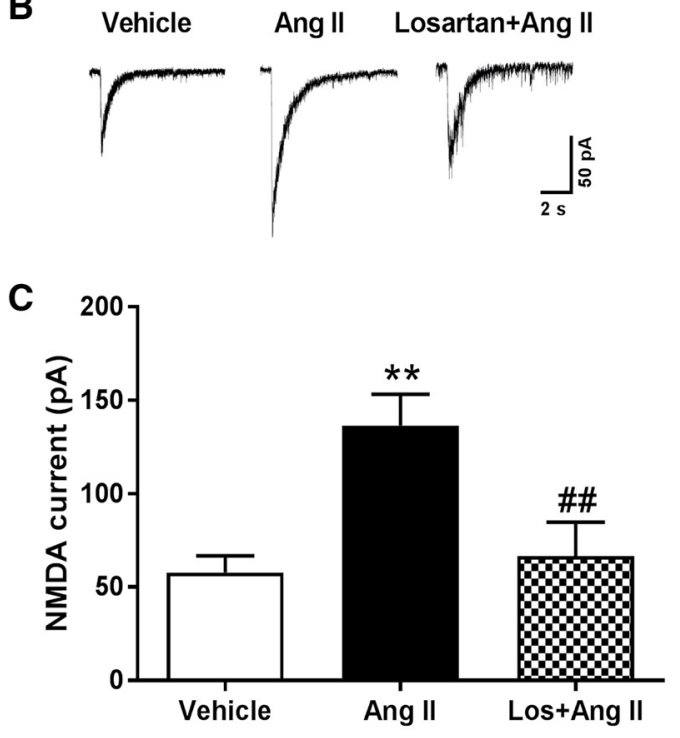

D
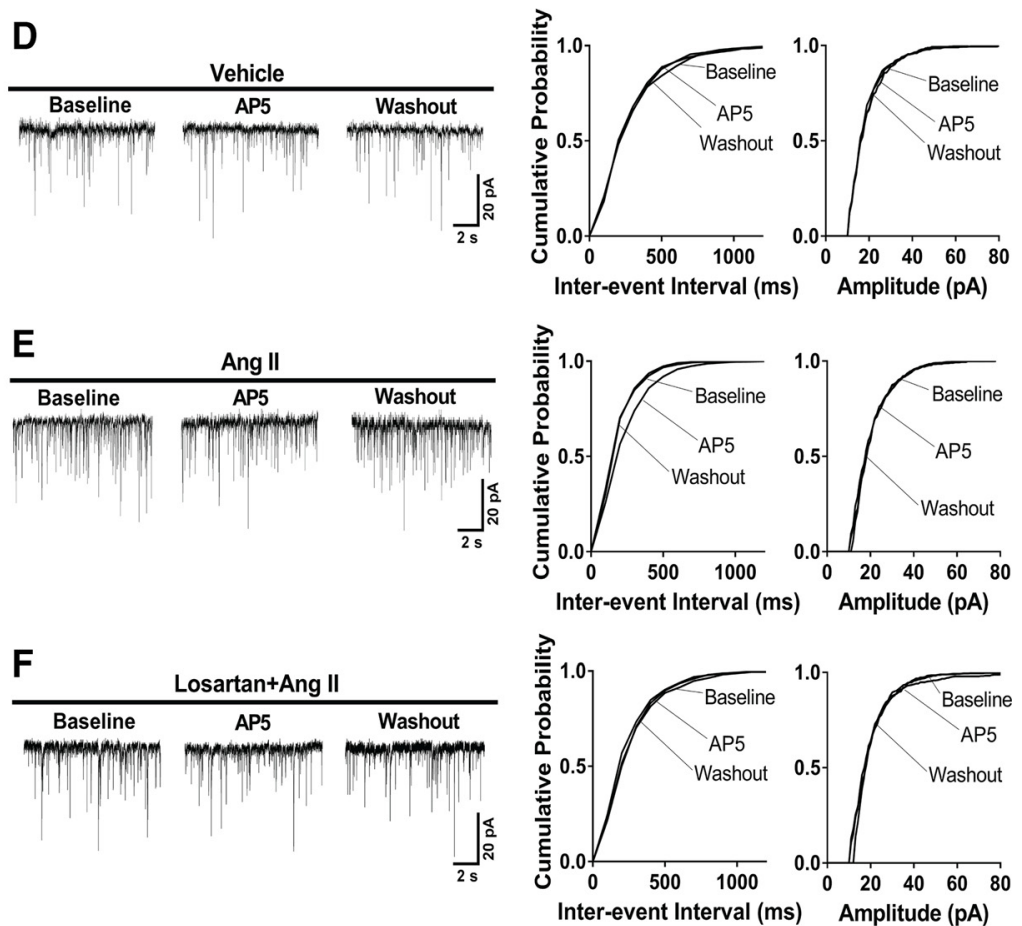

G

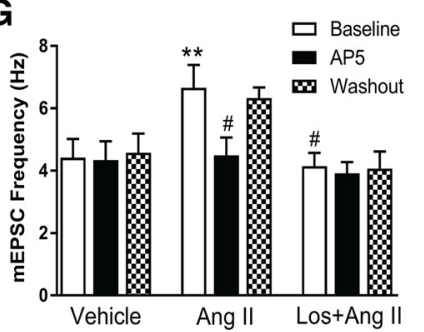

H

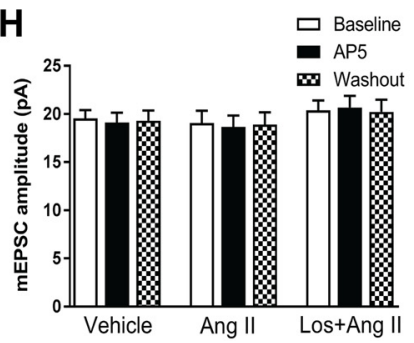

Figure 2. Ang II increases presynaptic and postsynaptic NMDAR activity via AT1 receptors in spinally projecting PVN neurons. $\boldsymbol{A}$, Identification of a retrogradely labeled spinally projecting PVN neuron. FluoSphere-labeled PVN neuron in the slice viewed with fluorescence illumination $(\boldsymbol{a})$. Photomicrograph $(\boldsymbol{b})$ of the same neuron shown in $\boldsymbol{a}$ with an attached recording electrode in the slice viewed with differential interference contrast optics. $B, C$, Original traces and mean changes show NMDAR currents elicited by the puff application of $100 \mu$ mol/L NMDA to labeled PVN neurons in brain slices preincubated with vehicle ( $n=8$ neurons), Ang II ( $2 \mu \mathrm{mol} / \mathrm{L}, n=11$ neurons), or losartan (Los, $2 \mu \mathrm{mol} / \mathrm{L})$ plus Ang II ( $n=8$ neurons). $\boldsymbol{D}-\boldsymbol{F}$, Representative current traces (left) and cumulative plots (right) of the mEPSCs of three separate labeled PVN neurons before bath application of $50 \mu \mathrm{mol} / \mathrm{L}$ AP5 (Baseline), with bath application of $50 \mu \mathrm{mol} / \mathrm{L}$ AP5 (AP5), and after washout (Washout) in brain slices pretreated with vehicle, Ang II, or losartan plus Ang II. $\mathbf{G}, \boldsymbol{H}$, Mean changes show the frequency and amplitude of mEPSCs and the AP5 effect in labeled PVN neurons pretreated with vehicle ( $n=8$ neurons), $2 \mu \mathrm{mol} /$ L Ang II ( $n=8$ neurons), or Ang II plus $2 \mu \mathrm{mol} / \mathrm{L}$ losartan (Los; $n=7$ neurons). Data are presented as means \pm SEM. ${ }^{* *} p<0.01$ compared with the baseline value of the vehicle group. $\# p<0.05$, \#\#p $<0.01$ compared with the Ang II effect.

synaptic glutamate. In contrast, AP5 application had no effect on the frequency of the mEPSCs of labeled PVN neurons in vehicletreated slices $(n=8$ neurons in each group; Fig. $2 D-H)$. The effect of Ang II on mEPSCs was blocked by pretreatment with 2 $\mu \mathrm{mol} / \mathrm{L}$ losartan (Li et al., 2003; $n=7$ neurons; Fig. 2D-H). These data suggest that Ang II increases presynaptic and postsynaptic NMDAR activity in PVN presympathetic neurons via AT1 receptors.

$\alpha 2 \delta$-1 Activity is required for Ang II's effect on presynaptic and postsynaptic NMDAR activity in PVN presympathetic neurons

$\alpha 2 \delta$-1 Is a highly glycosylated protein involved in protein trafficking. Both gabapentin and pregabalin bind predominantly to $\alpha 2 \delta-1$ (Gee et al., 1996; Wang et al., 1999; Marais et al., 2001; Fuller-Bicer et al., 2009) and act as an inhibitory $\alpha 2 \delta$ - 1 ligand. In contrast to the potentiating effect of Ang II on the amplitude of NMDAR currents elicited by puff application of NMDA in labeled PVN neurons treated with vehicle ( $n=10$ neurons), Ang II had no significant effect on puff NMDA currents in brain slices pretreated with pregabalin ( $n=7$ neurons; Fig. $3 A, B)$.

Although it stimulated the mEPSC frequency in vehicletreated slices ( $n=9$ neurons), Ang II failed to increase the frequency of mEPSCs of labeled PVN neurons in brain slices treated with pregabalin $(20 \mu \mathrm{mol} / \mathrm{L}$ for $30-60 \mathrm{~min}, n=9$ neurons; Fig. $3 E, F)$. Furthermore, bath application of AP5 (50 $\mu \mathrm{mol} / \mathrm{L}) \mathrm{read}-$ ily normalized the frequency of mEPSCs increased by Ang II plus vehicle but had no effect on the mEPSC frequency in brain slices treated with Ang II plus pregabalin (Fig. $3 C-F$ ). These data suggest that $\alpha_{2} \delta$ - 1 mediates the Ang II-induced increases in presynaptic and postsynaptic NMDAR activity in PVN presympathetic neurons.

Disrupting the $\alpha 2 \delta$-1-NMDAR interaction abolishes Ang II's effect on presynaptic and postsynaptic NMDAR activity in PVN presympathetic neurons

We next used the $\alpha 2 \delta$-1Tat peptide to determine whether $\alpha_{2} \delta$-1bound NMDARs are required for the Ang II effect on synaptic 
A
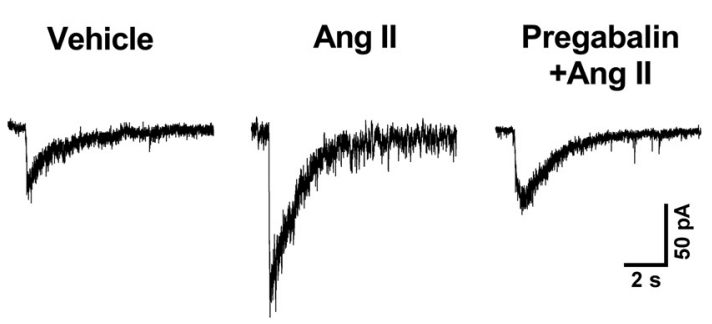

C

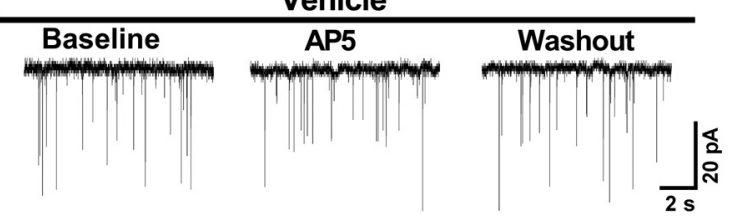

D

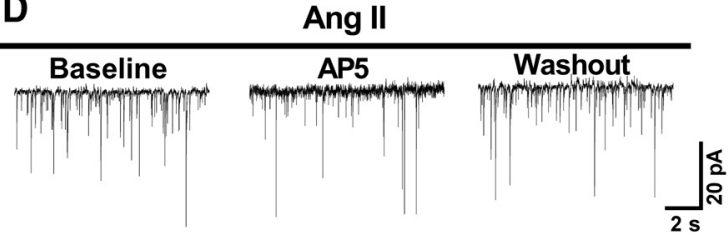

E

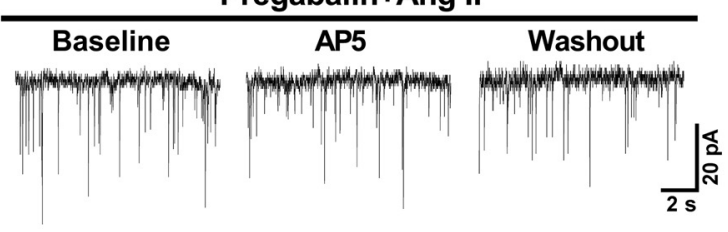

$\mathbf{F}$

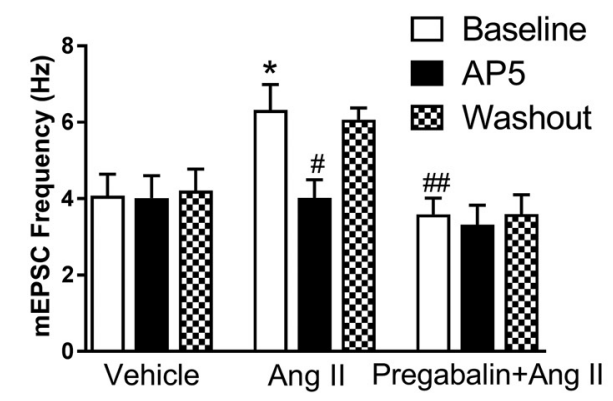

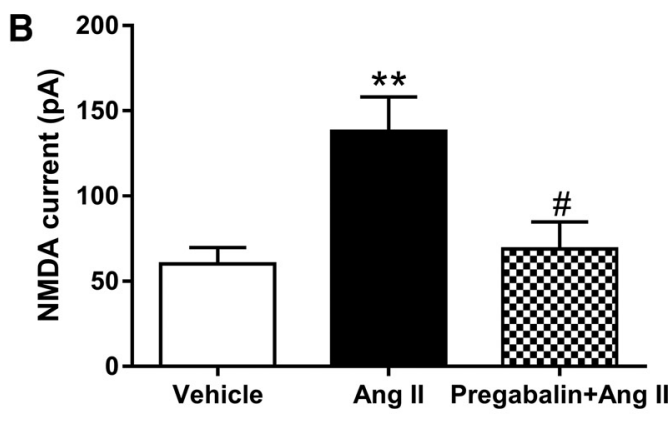
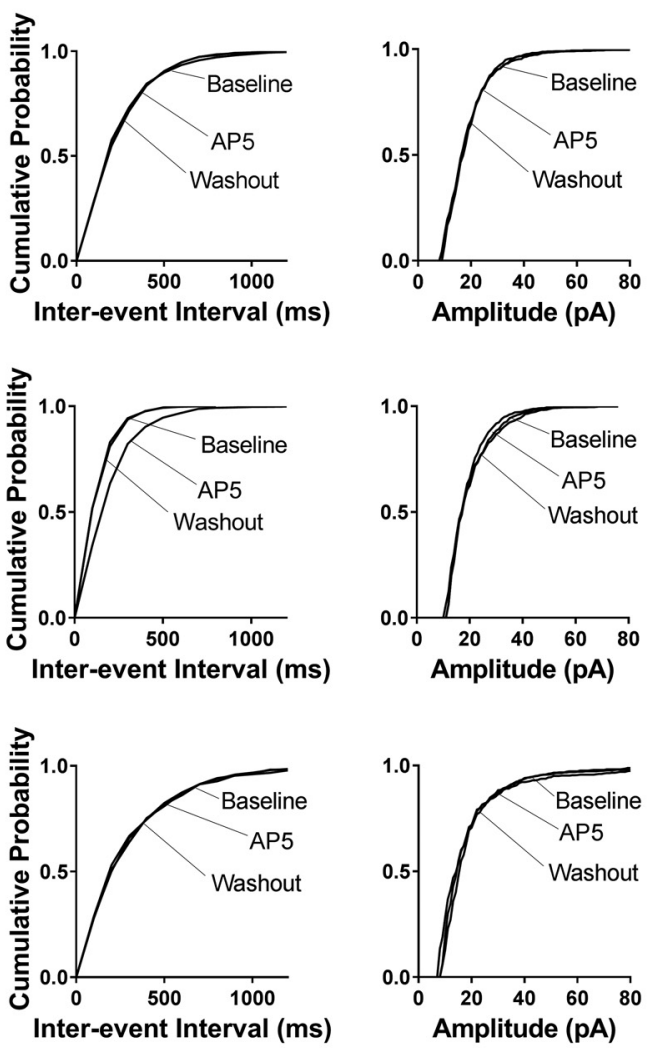

G

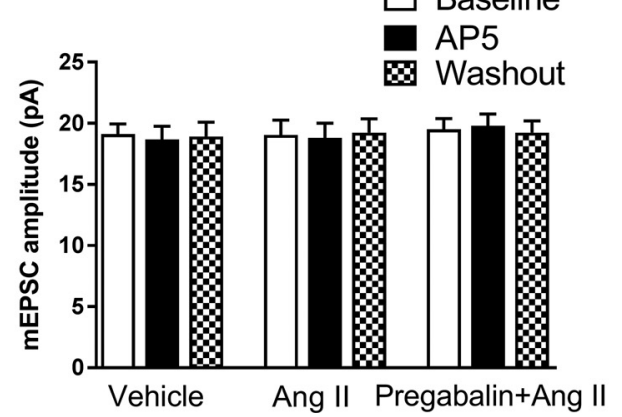

Figure 3. Pregabalin blocks the potentiating effect of Ang Il on presynaptic and postsynaptic NMDAR activity in spinally projecting PVN neurons. $A, B$, Original recording traces and mean changes of NMDAR currents elicited by the puff application of $100 \mu \mathrm{mol} / \mathrm{L} \mathrm{NMDA} \mathrm{to} \mathrm{labeled} \mathrm{PVN} \mathrm{neurons} \mathrm{in} \mathrm{brain} \mathrm{slices} \mathrm{treated} \mathrm{with} \mathrm{vehicle} \mathrm{plus} 2 \mu \mathrm{mol} / \mathrm{L}$ Ang $I I$ ( $n=10$ neurons) or $20 \mu \mathrm{mol} / \mathrm{L}$ pregabalin plus Ang II ( $n=7$ neurons). Labeled neurons without Ang II treatment were used as the control ( $n=8$ neurons). \#p $<0.05$ compared with the Ang II effect; ${ }^{* *} p<0.01$ compared with the vehicle group. C-E, Representative traces and cumulative plots show the mEPSCs of labeled PVN neurons before bath application of $50 \mu \mathrm{mol} / \mathrm{L}$ AP 5 (Baseline), with bath application of $50 \mu \mathrm{mol} / \mathrm{L}$ AP5 (AP5), and after washout (Washout) in brain slices treated with vehicle plus Ang II or pregabalin plus Ang II. F, G, Mean changes show the frequency and amplitude of $\mathrm{mEPSC}$ in labeled PVN neurons treated with vehicle plus $2 \mu \mathrm{mol} / \mathrm{L}$ Ang II ( $n=9$ neurons) or $20 \mu \mathrm{mol} / \mathrm{L}$ pregabalin plus Ang II ( $n=9$ neurons). Labeled neurons without Ang II treatment were used as the control ( $n=7 \mathrm{neurons}$ ). Data are presented as means \pm SEM. ${ }^{*} p<0.05$ compared with the baseline of the vehicle group. \#p $<0.05, \# p<0.01$ compared with the baseline of the Ang II group. 
A

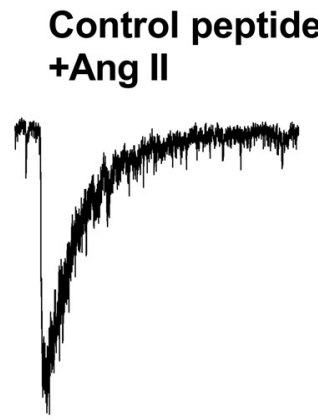

B

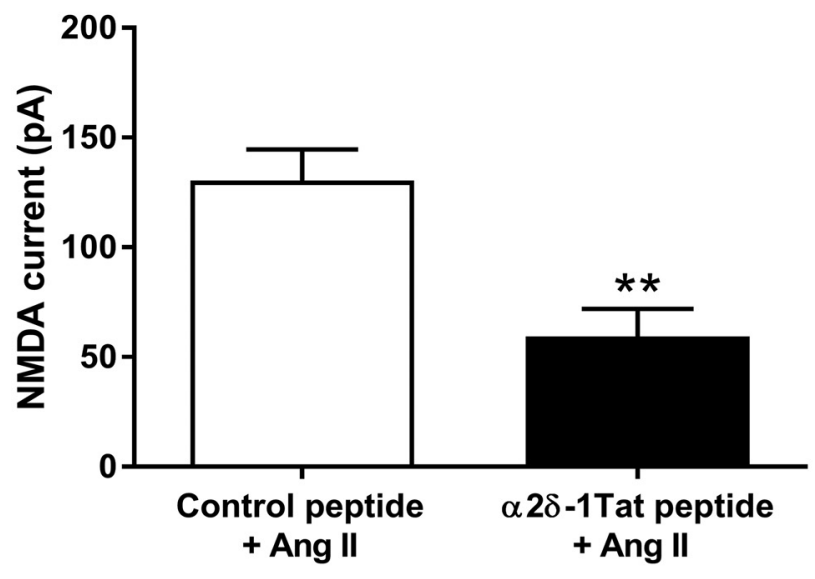

C

Control peptide+Ang II

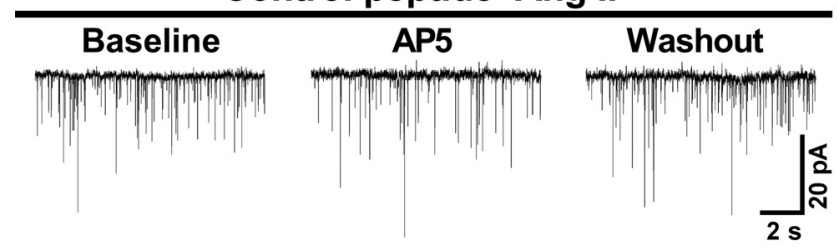

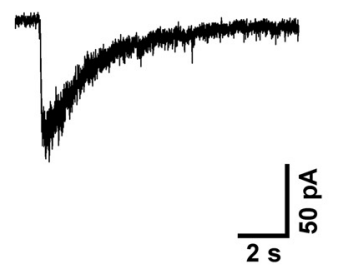

D

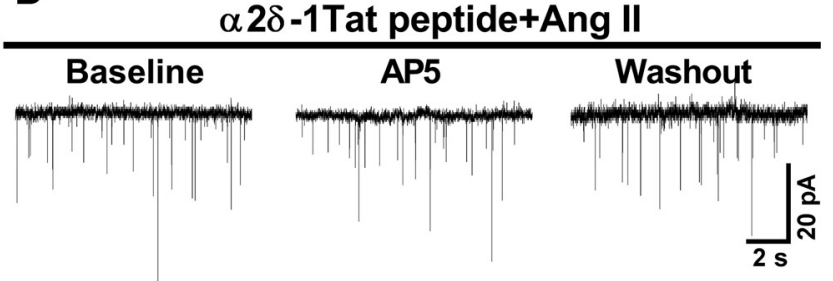

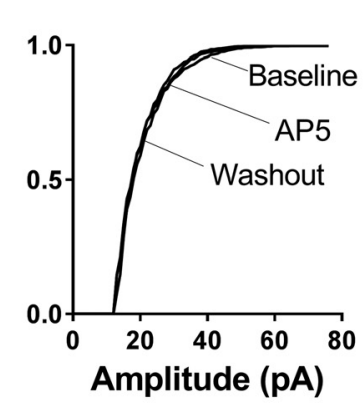

Inter-event Interval (ms)
E

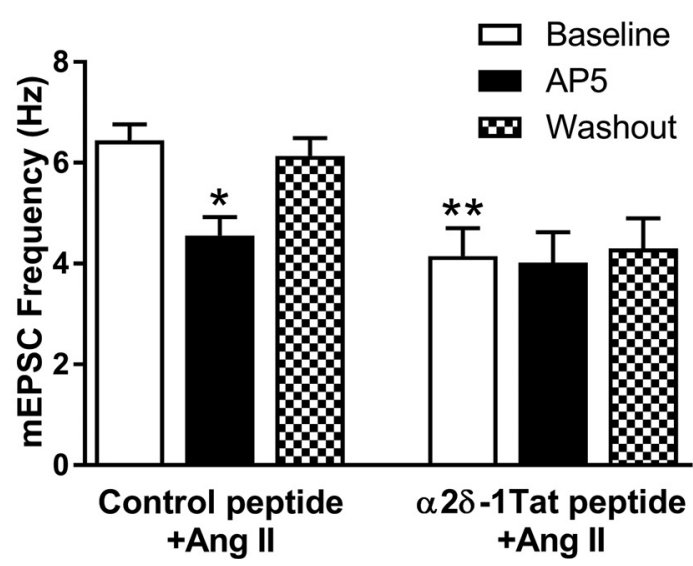

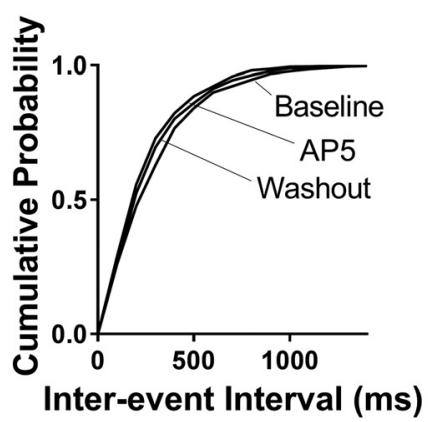

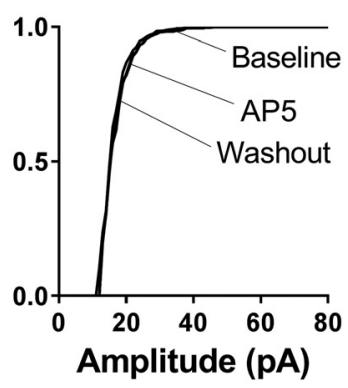

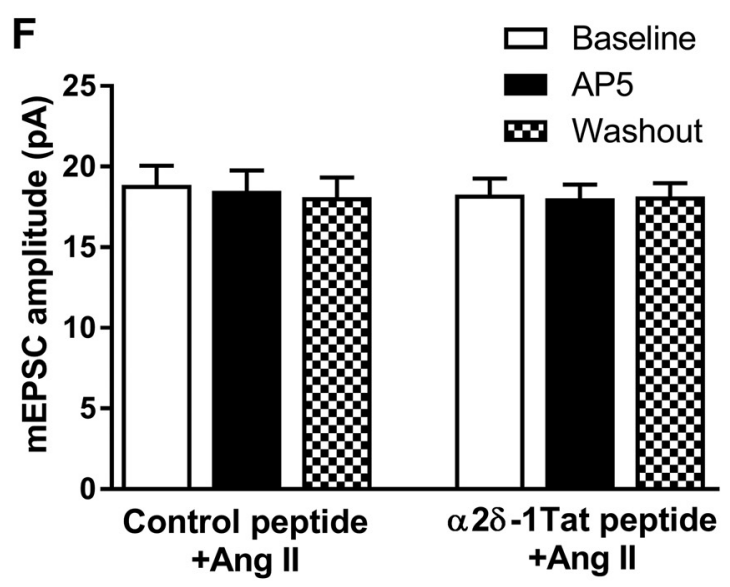

Figure 4. $\alpha 2 \delta$-1Tat peptide abrogates the potentiating effect of Ang II on presynaptic and postsynaptic NMDAR activity in spinally projecting PVN neurons. $A, B$, Original recording traces and mean changes of NMDAR currents elicited by the puff application of $100 \mu \mathrm{mol} / \mathrm{L} \mathrm{NMDA} \mathrm{to} \mathrm{labeled} \mathrm{PVN} \mathrm{neurons} \mathrm{in} \mathrm{brain} \mathrm{slices} \mathrm{treated} \mathrm{with} 1 \mu \mathrm{mol} / \mathrm{L}$ control peptide plus $2 \mu \mathrm{mol} / \mathrm{L}$ Ang $I I(n=13$ neurons) or $1 \mu \mathrm{mol} / \mathrm{L} \alpha 2 \delta$-1Tat peptide plus $2 \mu \mathrm{mol} / \mathrm{L}$ Ang $I I$ ( $n=9$ neurons). $C, D$, Representative traces and cumulative plots show mEPSCs of labeled PVN neurons before bath application of 50 $\mu \mathrm{mol} / \mathrm{L}$ AP5 (Baseline), with bath application of $50 \mu \mathrm{mol} / \mathrm{L}$ AP5 (AP5), and after washout (Washout) in brain slices treated with control peptide plus Ang II or $\alpha 2 \delta$-1Tat peptide plus Ang II. $\boldsymbol{E}, \boldsymbol{F}$, Mean changes show the frequency and amplitude of mEPSCs in labeled PVN neurons treated with control peptide plus Ang II ( $n=9$ neurons) or with $\alpha 2 \delta$-1Tat peptide plus Ang II ( $n=8$ neurons). Data are presented as means \pm SEM. ${ }^{*} p<0.05,{ }^{* *} p<0.01$ compared with the baseline of the control peptide plus Ang II group. 
A

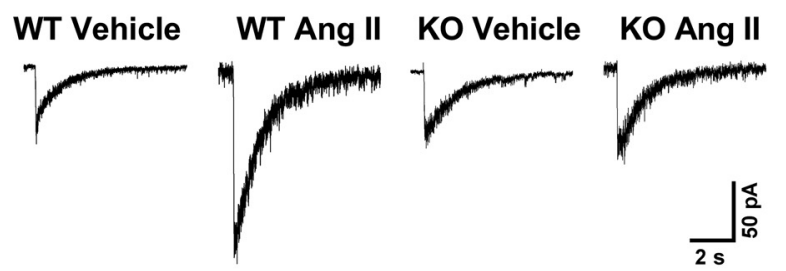

C

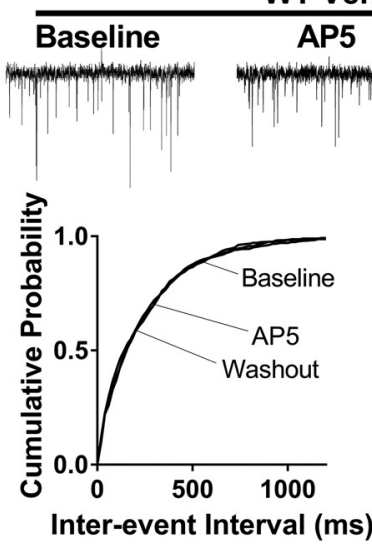

VT Vehicle

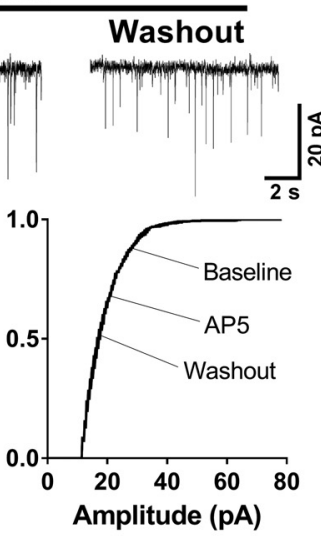

E

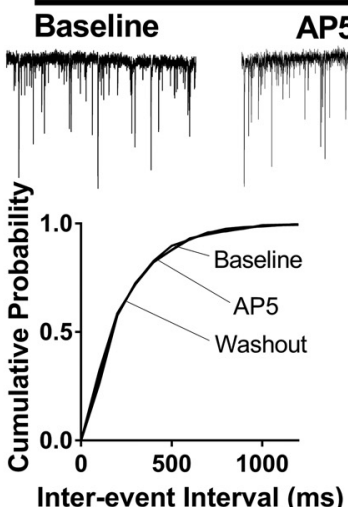

KO Vehicle

AP5
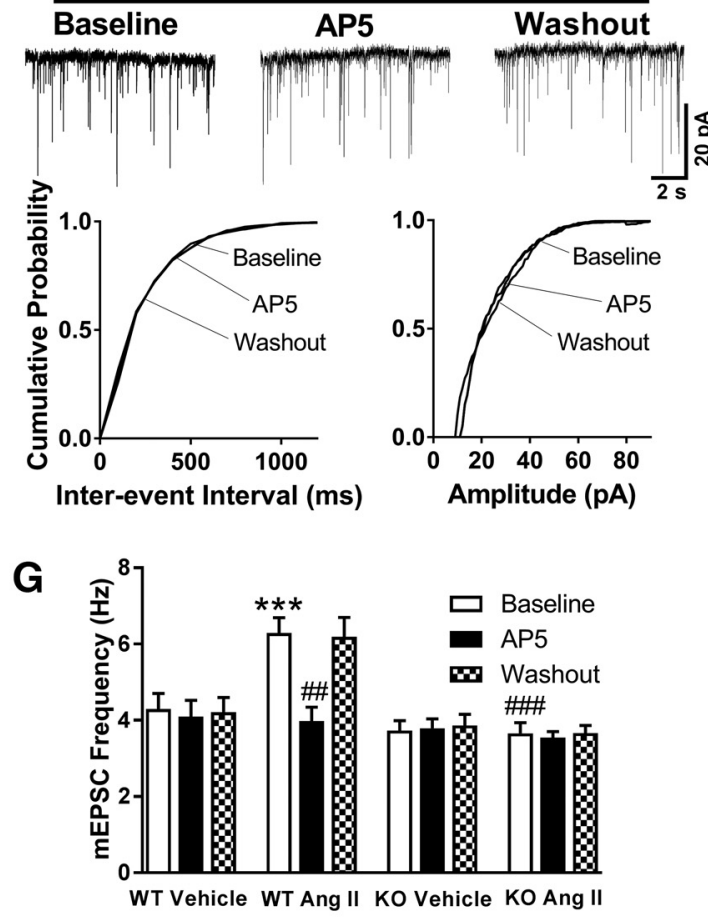

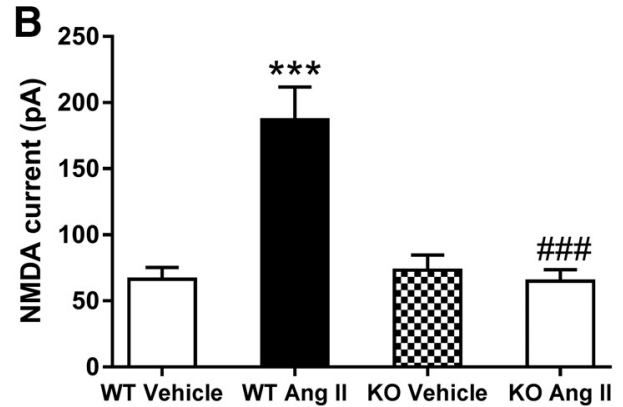

D

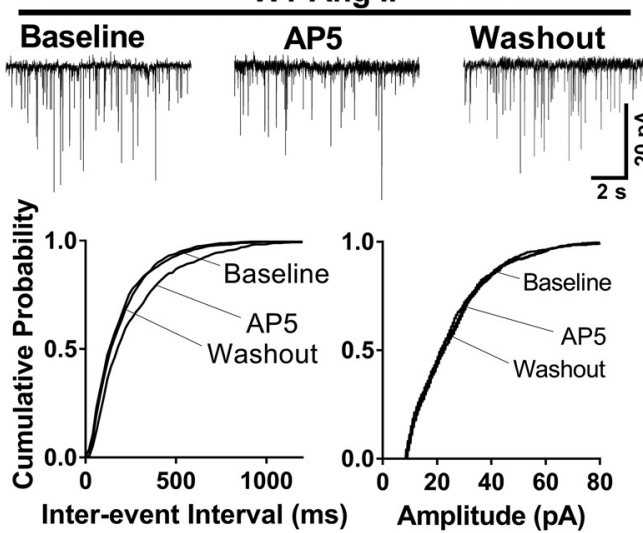

$\mathbf{F}$

KO Ang II
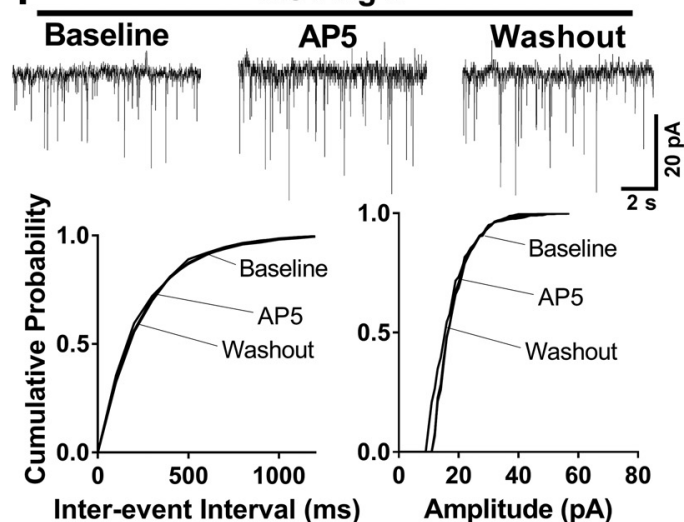

Inter-event Interval (ms)

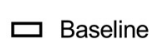

H

- AP5

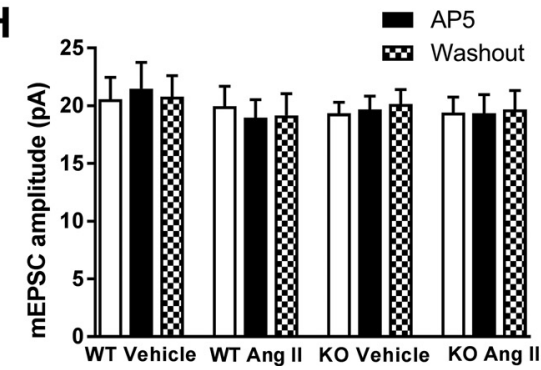

Figure 5. $\alpha 2 \delta$-1 Ablation abolishes the potentiating effect of Ang Il on presynaptic and postsynaptic NMDAR activity in spinally projecting PVN neurons of mice. $A, B, 0$ riginal traces $(A)$ and mean changes $(\boldsymbol{B})$ show NMDAR currents elicited by puff application of $100 \mu \mathrm{mol} / \mathrm{L}$ NMDA to labeled PVN neurons in brain slices treated with vehicle or $2 \mu \mathrm{mol} / \mathrm{L}$ Ang $/ \mathrm{l}$ in wild-type (WT, vehicle: $n=11$ neurons; Ang Il: $n=9$ neurons) and Cacna2d 1 knock-out (K0, vehicle: $n=14$ neurons; Ang II: $n=10$ neurons) mice. ${ }^{* *} p<0.001$ compared with the WT vehicle group. \#\#\# $<0.001$ compared with the WT Ang II group. $\mathbf{C}-\boldsymbol{F}$, Representative traces and cumulative plots of mEPSCs in labeled PVN neurons of WT and Cacna2d 1 K0 mice before bath application of $50 \mu$ mol/LAP5 (Baseline), with bath application of $50 \mu \mathrm{mol} / \mathrm{L}$ AP5 (AP5), and after washout (Washout) in brain slices treated with vehicle or $2 \mu \mathrm{mol} / \mathrm{L}$ Ang $I I . \mathbf{G}, \boldsymbol{H}$, Mean changes show the effect of AP5 on the frequency and amplitude of mEPSCs in the labeled PVN neurons of brain slices from WT mice ( $n=8$ neurons per group) and Cacna2d $1 \mathrm{~K} 0$ mice ( $n=9$ neurons per group) treated with vehicle or with $2 \mu$ mol/L Ang II. Data are presented as means \pm SEM. ${ }^{* * *} p<0.001$ compared with the baseline value of WT mice treated with vehicle.\#\#p $<0.01$, \#\#p $<0.001$ compared with the baseline value of WT mice treated with Ang II. 
A

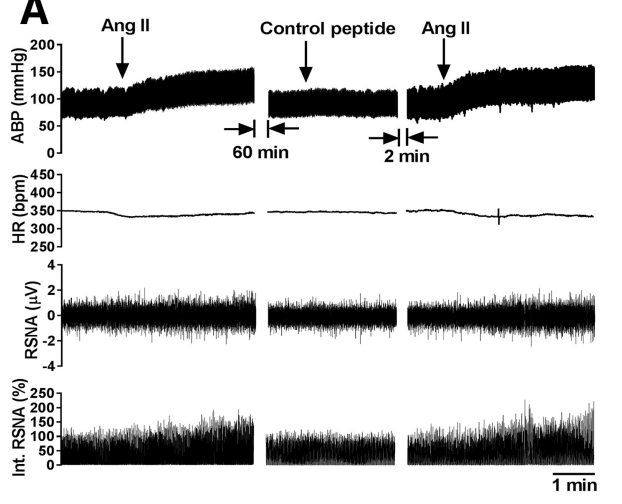

C

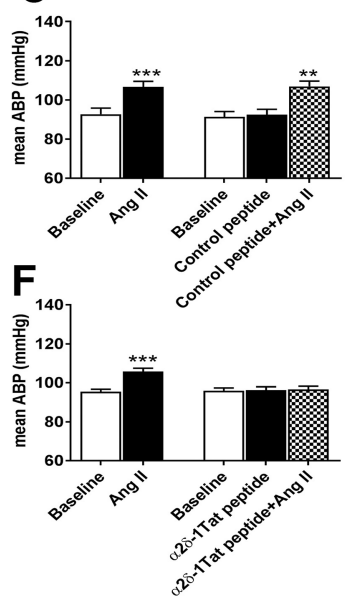

B

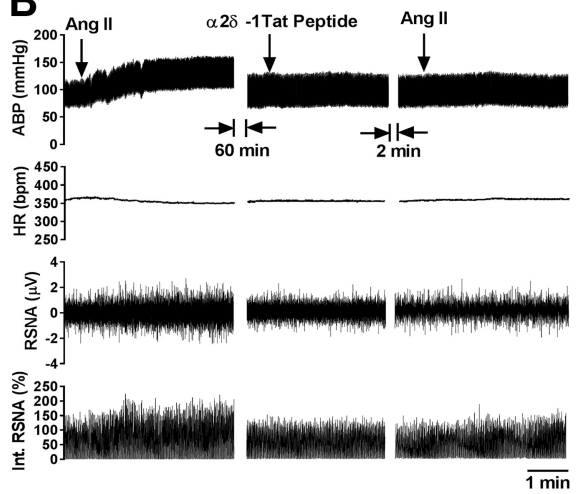

$\mathbf{E}$

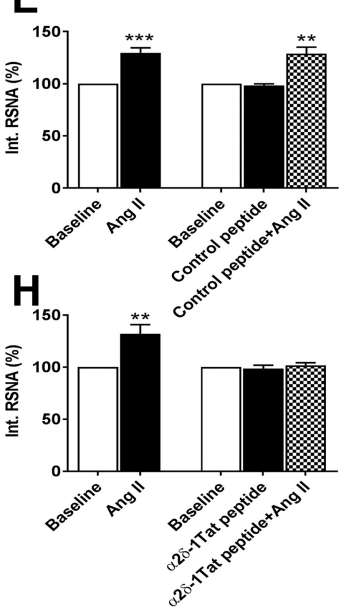

I

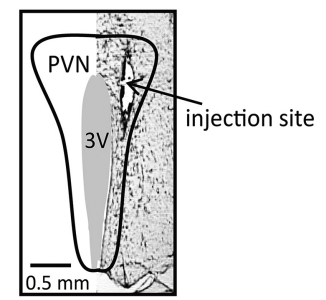

$\mathbf{J}$

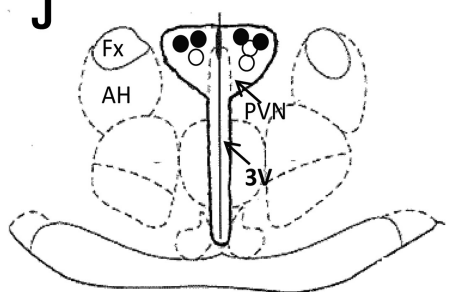

Bregma $-1.4 \mathrm{~mm}$
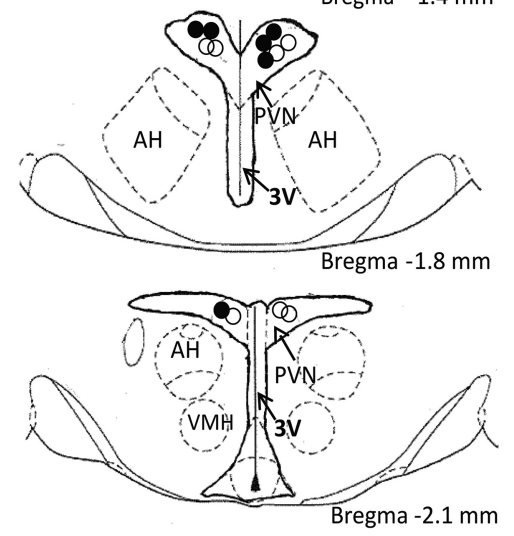

Figure 6. $\alpha 2 \delta$-1Tat peptide blocks sympathoexcitatory responses to the microinjection of Ang Ill into the PVN. $\boldsymbol{A}, \boldsymbol{B}$, Representative recording traces show the effect of bilateral microinjection of Ang II on ABP, RSNA, and HR in anesthetized rats before and after microinjection of the control peptide $(\boldsymbol{A})$ or $\alpha 2 \delta$-1Tat peptide $(\boldsymbol{B})$ into the PVN. $\boldsymbol{C}-\boldsymbol{H}$, Summary data show changes in mean ABP, RSNA, and HR in response to microinjection of Ang II before and after microinjection of the control peptide ( $\boldsymbol{C}-\boldsymbol{E}, n=10$ rats) or $\alpha 2 \delta$-1Tat peptide $(\boldsymbol{F}-\boldsymbol{H}, n=10$ rats) into the PVN. Data are presented as means \pm SEM. ${ }^{* *} p<0.01,{ }^{* * *} p<0.001$, compared with the baseline value. $I, J$, A representative image $(I)$ and schematic drawing $(J)$ show the microinjection sites (solid circle, rats treated with control peptide; open circle, rats treated with $\alpha 2 \delta$-1Tat peptide) in the PVN tissue sections. 3V, Third ventricle; AH, anterior hypothalamus; Fx, fornix; VMH, ventromedial hypothalamus.

NMDAR activity of spinally projecting PVN neurons. In brain slices pretreated with $\alpha 2 \delta$-1Tat peptide ( $1 \mu \mathrm{mol} / \mathrm{L}, 30 \mathrm{~min})$, Ang II $(2 \mu \mathrm{mol} / \mathrm{L})$ had no effect on the amplitude of puff NMDA currents of labeled PVN neurons ( $n=9$ neurons). In contrast, Ang II significantly increased the amplitude of puff NMDA currents in the presence of the control peptide $(1 \mu \mathrm{mol} / \mathrm{L}, 30 \mathrm{~min}$; $n=13$ neurons; Fig. $4 A, B)$.

In brain slices incubated with the $\alpha 2 \delta$-1Tat peptide, Ang II failed to increase the frequency of mEPSCs in all labeled PVN neurons ( $n=8$ neurons; Fig. $4 D, E$ ). However, a Tat-fused scrambled control peptide did not affect the stimulating effect of Ang II on the mEPSC frequency in separate labeled PVN neurons $(n=9$ neurons; Fig. $4 C, E)$. Bath application of AP5 $(50 \mu \mathrm{mol} / \mathrm{L})$ normalized the increased frequency of mEPSCs in brain slices treated with Ang II plus the control peptide but had no effect on the mEPSC frequency in brain slices treated with Ang II plus $\alpha 2 \delta$-1Tat peptide (Fig. $4 C-F$ ). These findings indicate that $\alpha 2 \delta$ 1-bound NMDARs are essential for Ang II-induced increases in the presynaptic and postsynaptic NMDAR activity of PVN presympathetic neurons.

$\alpha 2 \delta$-1 Is required for Ang II's effect on presynaptic and postsynaptic NMDAR activities in PVN presympathetic neurons

Because pharmacological agents may produce off-target effects, we next used Cacna2d1 knock-out $\left(\right.$ Cacna $\left.2 \mathrm{~d}^{-1-}\right)$ mice to vali- date the critical role of $\alpha 2 \delta$-1 in the Ang II-induced increase in synaptic NMDAR activity. In wild-type $\left(\right.$ Cacna $\left.2 d 1^{+/+}\right)$mice, Ang II treatment markedly increased the amplitude of puff NMDA-elicited currents ( $n=8$ neurons per group; Fig. $5 A, B$ ) and the NMDARmediated frequency of mEPSCs $(n=8$ neurons per group; Fig. $5 \mathrm{C}-\mathrm{H}$ ) in spinally projecting $\mathrm{PVN}$ neurons. In contrast, in Cacna2d $1^{-1-}$ mice, Ang II treatment had no effect on the amplitude of puff NMDA-elicited currents ( $n=10$ neurons per group) or on the frequency of mEPSCs ( $n=9$ neurons per group) in labeled PVN neurons. These data provide unequivocal evidence showing that $\alpha 2 \delta-1$ is essential for Ang II-induced increases in the synaptic NMDAR activity of PVN presympathetic neurons.

$\alpha 2 \delta$-1-Bound NMDARs are critically involved in the sympathoexcitatory responses to Ang II in the PVN In addition, we wanted to find out whether $\alpha 2 \delta$-1-bound NMDARs in the PVN play a role in sympathoexcitatory responses to Ang II in vivo. Because pregabalin and gabapentin bind to both $\alpha 2 \delta$-1 and $\alpha 2 \delta$-2 (Gee et al., 1996; Gong et al., 2001; Marais et al., 2001; Li et al., 2011), we used the $\alpha 2 \delta$-1Tat peptide, which selectively targets and disrupts the $\alpha 2 \delta$-1-NMDAR association (Chen et al., 2018). We examined the sympathoexcitatory responses elicited by microinjection of Ang II in the PVN in the presence of $\alpha 2 \delta$-1Tat peptide or the control peptide. As reported previously (Khanmoradi and Nasimi, 2016), microinjection of Ang II (200 $\mu \mathrm{mol} / \mathrm{L}, 50$ nl) into the PVN in anesthetized rats significantly increased the 
RSNA and mean ABP, and such effects were not altered by prior microinjection of the control peptide ( $n=10$ rats; Fig. $6 A-H)$. In contrast, when $\alpha 2 \delta$-1Tat peptide ( $100 \mu \mathrm{mol} / \mathrm{L}, 50 \mathrm{nl})$ was microinjected into the PVN, subsequent microinjection of Ang II into the PVN failed to significantly increase ABP and RSNA ( $n=10$ rats; Fig. $6 A, C-E)$. These data suggest that $\alpha 2 \delta$-1-bound NMDARs are required for the sympathoexcitatory responses to Ang II in the PVN.

\section{Discussion}

The most salient finding of our study is that a switch from $\alpha 2 \delta$-1-free to $\alpha 2 \delta$-1-bound NMDARs is essential for the Ang II-induced increase in synaptic NMDAR activity in the hypothalamus. We recently demonstrated that $\alpha 2 \delta$-1 interacts with NMDAR subunits in the spinal cord to maintain chronic pain after nerve injury (Chen et al., 2018). In the present study, we found that $\alpha 2 \delta$-1 physically interacts with NMDARs in the hypothalamus in both rats and humans. We also found that Ang II increases the protein levels of $\alpha 2 \delta$-1 and NMDARs in the hypothalamic synaptosomes and that blocking the $\alpha 2 \delta$-1-NMDAR interaction with $\alpha 2 \delta$-1Tat peptide abolishes this effect of Ang II. These findings suggest that Ang II increases the synaptic trafficking of $\alpha 2 \delta$-1-bound NMDARs in the hypothalamus. We showed previously that the $\alpha 2 \delta$-1-NMDAR interaction is increased after nerve injury when there is an excess of $\alpha 2 \delta-1$ in the spinal cord (Chen et al., 2018). Here we show that this interaction can occur quickly in the hypothalamus following brief Ang II treatment. Thus, $\alpha 2 \delta$ - 1 plays an important role in Ang II signaling and in the regulation of NMDARs in the brain.

The PVN, an important brain region controlling sympathetic outflow, sends long descending projections to the brainstem and spinal cord (Swanson and Sawchenko, 1983; Kannan et al., 1989; Coote et al., 1998). In the PVN, presynaptic NMDARs are latent and not functionally active under physiological conditions. However, presynaptic NMDARs of PVN presympathetic neurons become tonically activated in spontaneously hypertensive rats (Ye et al., 2011; Qiao et al., 2017). We showed in this study that Ang II stimulates presynaptic NMDARs, as Ang II caused a large increase in synaptic glutamate release, which was normalized by AP5, a selective NMDAR antagonist. Ang II also markedly increased the amplitude of puff NMDA-elicited currents, which were mediated by postsynaptic NMDARs, in PVN presympathetic neurons. Those effects were blocked by the AT1 receptor antagonist losartan. Thus, Ang II increases presynaptic and postsynaptic NMDAR activity to potentiate glutamatergic input to $\mathrm{PVN}$ presympathetic neurons through AT1 receptors. We found that inhibiting $\alpha 2 \delta$-1 activity with pregabalin abolished the effect of Ang II on presynaptic and postsynaptic NMDAR activity. Furthermore, disrupting the $\alpha 2 \delta$-1-NMDAR association with $\alpha 2 \delta$-1Tat peptide obliterated the Ang II effect on the presynaptic and postsynaptic NMDAR activity in PVN presympathetic neurons. In addition, the crucial role of $\alpha 2 \delta$-1 in the effect of Ang II on presynaptic and postsynaptic NMDAR activity in PVN presympathetic neurons was substantiated using Cacna2d1 knock-out mice. Because we recorded mEPSCs and puff NMDAR currents using a negative hold potential and in the presence of TTX, the effect of Ang II on synaptic NMDARs is likely independent of VACCs. Although $\alpha 2 \delta$-1 may also interact with thrombospondins to promote synaptogenesis (Eroglu et al., 2009), this cannot explain the rapid effects of Ang II and AP5 on mEPSCs. Collectively, our findings provide unambiguous evidence that $\alpha 2 \delta$-1-bound NMDARs are essential for the Ang II-induced increase in synaptic NMDAR activity in the PVN.
Our in vitro data showing that $\alpha 2 \delta$ - 1 is required for the Ang II-induced increase in synaptic NMDAR activity in the PVN prompted us to determine whether $\alpha 2 \delta$-1-bound NMDARs contribute to the in vivo sympathoexcitatory response to Ang II in the PVN. Circulating Ang II can affect PVN neurons via the circumventricular organs (with permeable blood-brain barrier) and by increasing the blood-brain barrier permeability in hypertension (Zhang et al., 2010; Biancardi et al., 2014). Direct microinjection of Ang II into the PVN produces a pressor response ( $\mathrm{Li}$ et al., 2006; Khanmoradi and Nasimi, 2016). Also, the importance of NMDARs in the PVN in regulating ABP is supported by the finding that GluN1 deletion in the PVN reduces the increase in ABP by systemic administration of Ang II in mice (Glass et al., 2015). Consistent with our synaptic recording data, we showed that disrupting the $\alpha 2 \delta$-1-NMDAR interaction with the $\alpha 2 \delta$-1Tat peptide blocked the pressor and sympathoexcitatory responses to Ang II in the PVN. Notably, clinical studies suggest that gabapentinoids are effective at reducing cardiovascular hemodynamic changes elicited by intubation in surgical patients (Fassoulaki et al., 2006; Bala et al., 2015; Doleman et al., 2016). The ability of pregabalin and $\alpha 2 \delta$-1Tat peptide to normalize presynaptic and postsynaptic NMDAR activity increased by Ang II suggests that increased synaptic NMDAR activity by Ang II is mediated entirely by $\alpha 2 \delta-1$ bound NMDARs. In light of this finding, it may be possible to target $\alpha 2 \delta$-1-bound NMDARs in the PVN to treat neurogenic hypertension without affecting normal NMDAR function.

In conclusion, we present our striking findings that $\alpha 2 \delta$-1 plays a pivotal role in Ang II-induced potentiation in synaptic NMDAR activity of PVN presympathetic neurons and that $\alpha 2 \delta$ 1-bound NMDARs are required for the sympathetic outflow and blood pressure responses induced by Ang II in the PVN. This new information advances our understanding of the molecular mechanism involved the interaction between the renin-angiotensin and sympathetic nervous systems and suggests that targeting $\alpha 2 \delta$-1 (with gabapentinoids) and $\alpha 2 \delta$-1-bound NMDARs (with $\alpha 2 \delta$ 1 Tat peptide) may be used as a new strategy for treating neurogenic hypertension.

\section{References}

Allen AM (2002) Inhibition of the hypothalamic paraventricular nucleus in spontaneously hypertensive rats dramatically reduces sympathetic vasomotor tone. Hypertension 39:275-280. CrossRef Medline

Bala I, Bharti N, Ramesh NP (2015) Effect of gabapentin pretreatment on the hemodynamic response to laryngoscopy and tracheal intubation in treated hypertensive patients. Acta Anaesthesiol Taiwan 53:95-98. CrossRef Medline

Biancardi VC, Son SJ, Ahmadi S, Filosa JA, Stern JE (2014) Circulating angiotensin II gains access to the hypothalamus and brain stem during hypertension via breakdown of the blood-brain barrier. Hypertension 63: 572-579. CrossRef Medline

Brown JT, Randall A (2005) Gabapentin fails to alter P/Q-type Ca2 + channelmediated synaptic transmission in the hippocampus in vitro. Synapse 55: 262-269. CrossRef Medline

Chen J, Li L, Chen SR, Chen H, Xie JD, Sirrieh RE, MacLean DM, Zhang Y, Zhou MH, Jayaraman V, Pan HL (2018) The $\alpha 2 \delta$ 1-NMDA receptor complex is critically involved in neuropathic pain development and gabapentin therapeutic actions. Cell Rep 22:2307-2321. CrossRef Medline

Cole RL, Lechner SM, Williams ME, Prodanovich P, Bleicher L, Varney MA, Gu G (2005) Differential distribution of voltage-gated calcium channel alpha-2 delta (alpha2delta) subunit mRNA-containing cells in the rat central nervous system and the dorsal root ganglia. J Comp Neurol 491: 246-269. CrossRef Medline

Coote JH, Yang Z, Pyner S, Deering J (1998) Control of sympathetic outflows by the hypothalamic paraventricular nucleus. Clin Exp Pharmacol Physiol 25:461-463. CrossRef Medline

DiBona GF (2000) Nervous kidney. Interaction between renal sympathetic 
nerves and the renin-angiotensin system in the control of renal function. Hypertension 36:1083-1088. CrossRef Medline

Doleman B, Sherwin M, Lund JN, Williams JP (2016) Gabapentin for the hemodynamic response to intubation: systematic review and metaanalysis. Can J Anaesth 63:1042-1058. CrossRef Medline

Edwards BS, Schwab TR, Zimmerman RS, Heublein DM, Jiang NS, Burnett JC Jr (1986) Cardiovascular, renal, and endocrine response to atrial natriuretic peptide in angiotensin II mediated hypertension. Circ Res 59: 663-667. CrossRef Medline

Eilam R, Malach R, Bergmann F, Segal M (1991) Hypertension induced by hypothalamic transplantation from genetically hypertensive to normotensive rats. J Neurosci 11:401-411. CrossRef Medline

Eroglu C, Allen NJ, Susman MW, O'Rourke NA, Park CY, Ozkan E, Chakraborty C, Mulinyawe SB, Annis DS, Huberman AD, Green EM, Lawler J, Dolmetsch R, Garcia KC, Smith SJ, Luo ZD, Rosenthal A, Mosher DF, Barres BA (2009) Gabapentin receptor alpha2delta-1 is a neuronal thrombospondin receptor responsible for excitatory CNS synaptogenesis. Cell 139:380-392. CrossRef Medline

Fassoulaki A, Melemeni A, Paraskeva A, Petropoulos G (2006) Gabapentin attenuates the pressor response to direct laryngoscopy and tracheal intubation. Br J Anaesth 96:769-773. CrossRef Medline

Fuller-Bicer GA, Varadi G, Koch SE, Ishii M, Bodi I, Kadeer N, Muth JN, Mikala G, Petrashevskaya NN, Jordan MA, Zhang SP, Qin N, Flores CM, Isaacsohn I, Varadi M, Mori Y, Jones WK, Schwartz A (2009) Targeted disruption of the voltage-dependent calcium channel alpha2/delta-1subunit. Am J Physiol Heart Circ Physiol 297:H117-H124. CrossRef Medline

Gee NS, Brown JP, Dissanayake VU, Offord J, Thurlow R, Woodruff GN (1996) The novel anticonvulsant drug, gabapentin (Neurontin), binds to the alpha2delta subunit of a calcium channel. J Biol Chem 271:57685776. CrossRef Medline

Glass MJ, Wang G, Coleman CG, Chan J, Ogorodnik E, Van Kempen TA, Milner TA, Butler SD, Young CN, Davisson RL, Iadecola C, Pickel VM (2015) NMDA receptor plasticity in the hypothalamic paraventricular nucleus contributes to the elevated blood pressure produced by angiotensin II. J Neurosci 35:9558-9567. CrossRef Medline

Gong HC, Hang J, Kohler W, Li L, Su TZ (2001) Tissue-specific expression and gabapentin-binding properties of calcium channel alpha2delta subunit subtypes. J Membr Biol 184:35-43. CrossRef Medline

Hoppa MB, Lana B, Margas W, Dolphin AC, Ryan TA (2012) alpha2delta expression sets presynaptic calcium channel abundance and release probability. Nature 486:122-125. CrossRef Medline

Kannan H, Hayashida Y, Yamashita H (1989) Increase in sympathetic outflow by paraventricular nucleus stimulation in awake rats. Am J Physiol 256:R1325-R1330. Medline

Khanmoradi M, Nasimi A (2016) Angiotensin II in the paraventricular nucleus stimulates sympathetic outflow to the cardiovascular system and make vasopressin release in rat. Neurosci Lett 632:98-103. CrossRef Medline

Li DP, Pan HL (2006) Plasticity of GABAergic control of hypothalamic presympathetic neurons in hypertension. Am J Physiol Heart Circ Physiol 290:H1110-H1119. CrossRef Medline

Li DP, Pan HL (2007) Glutamatergic inputs in the hypothalamic paraventricular nucleus maintain sympathetic vasomotor tone in hypertension. Hypertension 49:916-925. CrossRef Medline

Li DP, Chen SR, Pan HL (2002) Nitric oxide inhibits spinally projecting paraventricular neurons through potentiation of presynaptic GABA release. J Neurophysiol 88:2664-2674. CrossRef Medline

Li DP, Chen SR, Pan HL (2003) Angiotensin II stimulates spinally project- ing paraventricular neurons through presynaptic disinhibition. J Neurosci 23:5041-5049. CrossRef Medline

Li DP, Yang Q, Pan HM, Pan HL (2008) Pre- and postsynaptic plasticity underlying augmented glutamatergic inputs to hypothalamic presympathetic neurons in spontaneously hypertensive rats. J Physiol 586:1637-1647. CrossRef Medline

Li YF, Wang W, Mayhan WG, Patel KP (2006) Angiotensin-mediated increase in renal sympathetic nerve discharge within the PVN: role of nitric oxide. Am J Physiol Regul Integr Comp Physiol 290:R1035-R1043. CrossRef Medline

Li Z, Taylor CP, Weber M, Piechan J, Prior F, Bian F, Cui M, Hoffman D, Donevan S (2011) Pregabalin is a potent and selective ligand for alpha(2)delta-1 and alpha(2)delta-2 calcium channel subunits. Eur J Pharmacol 667:80-90. CrossRef Medline

Marais E, Klugbauer N, Hofmann F (2001) Calcium channel alpha(2)delta subunits-structure and gabapentin binding. Mol Pharmacol 59:12431248. CrossRef Medline

Qiao X, Zhou JJ, Li DP, Pan HL (2017) Src kinases regulate glutamatergic input to hypothalamic presympathetic neurons and sympathetic outflow in hypertension. Hypertension 69:154-162. CrossRef Medline

Richardson D, Stella A, Leonetti G, Bartorelli A, Zanchetti A (1974) Mechanisms of renal release of renin by electrical stimulation of the brainstem in the cat. Circ Res 34:425-434. CrossRef Medline

Rock DM, Kelly KM, Macdonald RL (1993) Gabapentin actions on ligandand voltage-gated responses in cultured rodent neurons. Epilepsy Res 16:89-98. CrossRef Medline

Schumacher TB, Beck H, Steinhäuser C, Schramm J, Elger CE (1998) Effects of phenytoin, carbamazepine, and gabapentin on calcium channels in hippocampal granule cells from patients with temporal lobe epilepsy. Epilepsia 39:355-363. CrossRef Medline

Strack AM, Sawyer WB, Hughes JH, Platt KB, Loewy AD (1989) A general pattern of CNS innervation of the sympathetic outflow demonstrated by transneuronal pseudorabies viral infections. Brain Res 491:156-162. CrossRef Medline

Swanson LW, Sawchenko PE (1983) Hypothalamic integration: organization of the paraventricular and supraoptic nuclei. Annu Rev Neurosci 6:269-324. CrossRef Medline

Taylor CP, Garrido R (2008) Immunostaining of rat brain, spinal cord, sensory neurons and skeletal muscle for calcium channel alpha2-delta (alpha2delta) type 1 protein. Neuroscience 155:510-521. CrossRef Medline

Tovar KR, Westbrook GL (2002) Mobile NMDA receptors at hippocampal synapses. Neuron 34:255-264. CrossRef Medline

Wang G, Coleman CG, Chan J, Faraco G, Marques-Lopes J, Milner TA, Guruju MR, Anrather J, Davisson RL, Iadecola C, Pickel VM (2013) Angiotensin II slow-pressor hypertension enhances NMDA currents and NOX2-dependent superoxide production in hypothalamic paraventricular neurons. Am J Physiol Regul Integr Comp Physiol 304:R1096-R1106. CrossRef Medline

Wang M, Offord J, Oxender DL, Su TZ (1999) Structural requirement of the calcium-channel subunit $\alpha 2 \delta$ for gabapentin binding. Biochem J 342: 313-320. CrossRef Medline

Ye ZY, Li DP, Li L, Pan HL (2011) Protein kinase CK2 increases glutamatergic input in the hypothalamus and sympathetic vasomotor tone in hypertension. J Neurosci 31:8271-8279. CrossRef Medline

Zhang M, Mao Y, Ramirez SH, Tuma RF, Chabrashvili T (2010) Angiotensin II induced cerebral microvascular inflammation and increased bloodbrain barrier permeability via oxidative stress. Neuroscience 171:852-858. CrossRef Medline 